\title{
A self-propagating high-temperature synthesis method for Ni-ferrite powder synthesis
}

\author{
Cheng-Hsiung Peng ${ }^{a}$, Chyi-Ching Hwang ${ }^{b, *}$, Ching-Kai Hong ${ }^{b}$, San-Yuan Chen ${ }^{a}$ \\ a Department of Materials Science and Engineering, National Chiao Tung University, Hsinchu 300, Taiwan, ROC \\ ${ }^{\mathrm{b}}$ Department of Applied Chemistry, Chung Cheng Institute of Technology, Tashi, Taoyuan 335, Taiwan, ROC
}

Received 17 June 2003; accepted 10 December 2003

\begin{abstract}
$\mathrm{Ni}$-ferrite $\left(\mathrm{NiFe}_{2} \mathrm{O}_{4}\right)$ powder was synthesized by a self-propagating high-temperature synthesis ( $\mathrm{SHS}$ ) process using $\mathrm{Fe}, \mathrm{Fe}_{2} \mathrm{O}_{3}$ and various $\mathrm{Ni}$-containing species (Ni-CSs) as reactants. The reactants were thoroughly mixed and pressed into a cylindrical compact. The compact was ignited by electrical heating under oxygen partial pressures varying between 0.02 and $1.5 \mathrm{MPa}$. The effects of the type of Ni-containing species, the reactant composition, the oxygen pressure on the combustion temperature, and the product conversion were investigated. X-ray diffraction (XRD) analysis showed that oxygen pressure promoted product conversion. Among several Ni-containing species tested, $\mathrm{Ni}_{2} \mathrm{O}_{3}$ was found to give the highest conversion. The product conversion increased with increasing iron content and then decreased with further increase in iron content. Scanning electron microscope (SEM) observations showed that the product synthesized is mostly in the form of agglomerated fine particles with submicron size $(0.1-0.5 \mu \mathrm{m})$. Hysteresis behavior analysis showed that the product as synthesized possessed better soft magnetic properties when compared with commercial Ni-ferrite prepared by the solid reaction method.
\end{abstract}

(c) 2004 Elsevier B.V. All rights reserved.

Keywords: Ferrite; SHS; Combustion synthesis; Ni-containing compound; Magnetic property

\section{Introduction}

Nickel ferrite, $\mathrm{NiFe}_{2} \mathrm{O}_{4}$, is an inverse spinel in which the tetrahedral sites (A) are occupied by $\mathrm{Fe}^{3+}$ ions and the octahedral sites (B) by $\mathrm{Fe}^{2+}$ and $\mathrm{Ni}^{2+}$ ions [1]. This material is largely used in electric and electronic devices and in catalysis [2].

Conventionally, oxide ceramic powders are made by solid-state reaction method $[3,4]$ which requires heating at elevated temperatures for long periods of time. In addition to high energy consumption, the production rate is slow. Recently, several wet chemical methods, such as the hydrothermal method, co-precipitation process, and sol-gel technique, have been developed for the synthesis of oxide ceramic powders to improve their properties [5-7]. These methods may have several drawbacks [8]: high $\mathrm{pH}$ sensitivity, stringent drying conditions, complex equipment and expensive precursors, and others. Moreover, any wet

\footnotetext{
* Corresponding author. Tel.: +886-3-3891716x312; fax: +886-3-3892711.

E-mail address: cchwang1@ccit.edu.tw (C.-C. Hwang).
}

chemical method, in general, needs calcination at a higher temperature to obtain the final powder product with the expected crystal structure.

Fortunately, the drawbacks of these methods can be partially eliminated by the combustion synthesis (SHS) method. The SHS method, originally developed in the former USSR [9], has been applied to the synthesis of various materials including ceramics, intermetallics, and composites [10,11]. The SHS method is a self-energetic reaction, possessing rapid heating and cooling. It has many potential advantages such as simple preparation, low processing cost, energy efficiency, and high production rate.

The synthesis of Ni-ferrite powder using the SHS method has not been reported so far, although there have been some attempts to obtain other oxide ceramics powders via SHS [12-14]. These studies reported that the ferrites could be synthesized through the combustion reactions of $\mathrm{Fe}, \mathrm{Fe}_{2} \mathrm{O}_{3}$ and other metal oxides under air or oxygen atmospheres. However, the effect of processing conditions in SHS requires further detailed investigation.

Hence, in this work, we focus on the use of SHS for the synthesis of Ni-ferrite powder. Five types of Ni-containing 
species (which will be referred to as Ni-CSs) were tested for their applicability in synthesis. Among them, $\mathrm{NiO}$ and $\mathrm{NiCO}_{3}$ are often used in conventional solid-state reaction in the manufacture of oxide ceramics. $\mathrm{Ni}_{2} \mathrm{O}_{3}$ and nickel nitrate possess the characteristics of oxidizing agents [15] and, in our opinion, they can be decomposed during combustion. $\mathrm{Ni}$ powder can be easily ignited to release a great amount of heat to propagate combustion. The SHS reaction can be expressed as:

$k \mathrm{Ni}-\mathrm{CS}+\alpha \mathrm{Fe}+\frac{1}{2}(2-\alpha) \mathrm{Fe}_{2} \mathrm{O}_{3} \stackrel{\mathrm{O}_{2}}{\rightarrow} \mathrm{NiFe}_{2} \mathrm{O}_{4}$

where $k=0.5$ for $\mathrm{Ni}_{2} \mathrm{O}_{3}, k=1$ for the other Ni-CSs, and $0 \leq \alpha \leq 2.0$. From the chemical formula of Ni-ferrite $\left(\mathrm{NiFe}_{2} \mathrm{O}_{4}\right)$, the stoichiometric ratio of $\mathrm{Fe}$ to $\mathrm{Ni}$ is equal to 2. The atomic ratio of $\mathrm{Fe} / \mathrm{Ni}$ was thus fixed at 2 in the present study. In this SHS reaction, iron powder is the fuel and oxygen is the oxidizer. Therefore, the effects of the iron content (i.e., $\alpha$ value) and oxygen pressure on the product conversion were also investigated.

\section{Experimental procedure}

Listed in Table 1 are the characteristics of the reagents used in this study. Iron, iron oxide and one kind of Ni-CS were mixed thoroughly at the desired ratios. Afterwards, $5 \mathrm{~g}$ of the mixture was pressed into a cylindrical compact (i.e., the reactant compact) with $15 \mathrm{~mm}$ in diameter and approximately $20 \mathrm{~mm}$ in length. A stainless steel die with two plungers was used and a pressure of $\sim 100 \mathrm{MPa}$ was uniaxially applied in forming the reactant compact.

The combustion synthesis reactor used in this study was shown schematically in our previous study [16]. The reactant compact was placed on a highly-adjustable stage in the reactor. The stage was adjusted so that the top surface of the reactant compact was $\sim 3 \mathrm{~mm}$ below the heating element. The reactor was evacuated and then backfilled with oxygen to the desired pressures. The synthesis reaction was ignited by heating the top surface of the reactant compact by passing an electric current (25-30 A, 35-40 V) through two nichrome coils connected in parallel. In some experiments, the synthesis reactions were carried out in air.

Table 1

Characteristics of the reagents used in the present study

\begin{tabular}{llll}
\hline Reagent & Purity $(\%)$ & $\begin{array}{l}\text { Particle size } \\
(\mu \mathrm{m})\end{array}$ & Source \\
\hline $\mathrm{Fe}$ & 99 & $\sim 1$ & Cerac \\
$\mathrm{Fe}_{2} \mathrm{O}_{3}$ & 99 & $\sim 1$ & Cerac \\
$\mathrm{Ni}$ & 99 & $<45$ & Cerac \\
$\mathrm{NiO}$ & 99 & $<45$ & Cerac \\
$\mathrm{Ni}_{2} \mathrm{O}_{3}$ & 92 & $<45$ & Strem Chemicals \\
$\mathrm{NiCO}_{3}$ & 99 & - & Waco Ltd. \\
$\mathrm{Ni}\left(\mathrm{NO}_{3}\right) \cdot 6 \mathrm{H}_{2} \mathrm{O}$ & $\mathrm{GR}$ grade & - & Waco Ltd. \\
$\mathrm{NiFe}_{2} \mathrm{O}_{4}$ & 99 & $\sim 2$ & Core Connector Co. Ltd., \\
& & & Taipei, Taiwan \\
\hline
\end{tabular}

Temperature variations during combustion were measured using a $0.127 \mathrm{~mm}$ in diameter Pt-Pt-10\% Ph thermocouple. The thermocouple with a $1.2 \mathrm{~mm}$ diameter alumina tube, was inserted into the center of the reactant compact through a pre-drilled hole. The signals from the thermocouple were stored and processed using a data acquisition system (Notebook, Labtech, Wilmington, MA).

The product formation was determined by X-ray diffractometry (XRD, Siemenz D5000, Germany). The microstructures of the reactant compact and combustion product were observed with a scanning electron microscope (SEM, Jeol 6400, Japan). Magnetic properties of the product powders determined by a vibrating sample magnetometer (VSM, Toei VSM-5, USA). For comparison, the magnetic property of a commercial Ni-ferrite produced by the solid reaction method was also measured. The details of the commercial $\mathrm{NiFe}_{2} \mathrm{O}_{4}$ are also listed in Table 1.

\section{Results and discussion}

\subsection{Visual observations of SHS reactions and time-temperature histories}

Typical temperature histories at the centers of the reactant compacts using various $\mathrm{Ni}-\mathrm{CS}$ s during SHS reaction are shown in Fig. 1. Taking the case of $\mathrm{NiO}+\mathrm{Fe}_{2} \mathrm{O}_{3}+\mathrm{Fe}$ as an example, once the reactant compact was ignited, a combustion reaction took place at the top of the compact (evidenced by a red glow) and the combustion wave propagated down to the bottom. The temperature increased rapidly up to a maximum of $\sim 975^{\circ} \mathrm{C}$ and then the temperature began to decrease slowly (see Fig. 1(a)). The rapid increase in temperature is caused both by the heating resulting from the combustion of the upper adjacent layer and by its own combustion. The maximum temperature during SHS reaction is defined as the combustion temperature $\left(T_{\mathrm{c}}\right)$. In the reactant compact composed of $\mathrm{Ni}_{2} \mathrm{O}_{3}+\mathrm{Fe}_{2} \mathrm{O}_{3}+\mathrm{Fe}$, the combustion temperature is approximately $1100^{\circ} \mathrm{C}$ (Fig. 1(b)). In addition, a shoulder is observed in the temperature profile between 640 and $700^{\circ} \mathrm{C}$. This shoulder temperature range corresponds to the temperature of nickel peroxide endothermic decomposition to $\mathrm{NiO}$ and oxygen [15]. According to experimental observations, a violent gas evolution occurred during the combustion reaction and the appearance of the synthesized product became highly porous. These events may be caused by $\mathrm{O}_{2}$ generated by the decomposition of $\mathrm{Ni}_{2} \mathrm{O}_{3}$ which flowed out of the reactant compact. When using $\mathrm{NiCO}_{3}$ as the $\mathrm{Ni}-\mathrm{CS}$, evolution of smoke from the surface of the reactant compact was also observed. As can be seen in Fig. 1(c), there is a plateau in the temperature range between 270 and $310^{\circ} \mathrm{C}$, which may be associated with the decomposition of $\mathrm{NiCO}_{3}$ to $\mathrm{NiO}$ and $\mathrm{CO}_{2}$ [15]. In this case, the combustion temperature is $\sim 950^{\circ} \mathrm{C}$. When using $\mathrm{Ni}+\mathrm{Fe}_{2} \mathrm{O}_{3}+\mathrm{Fe}$ as the reactants, the SHS reaction was vigorous and the combustion temperature could not be measured because the thermocou- 


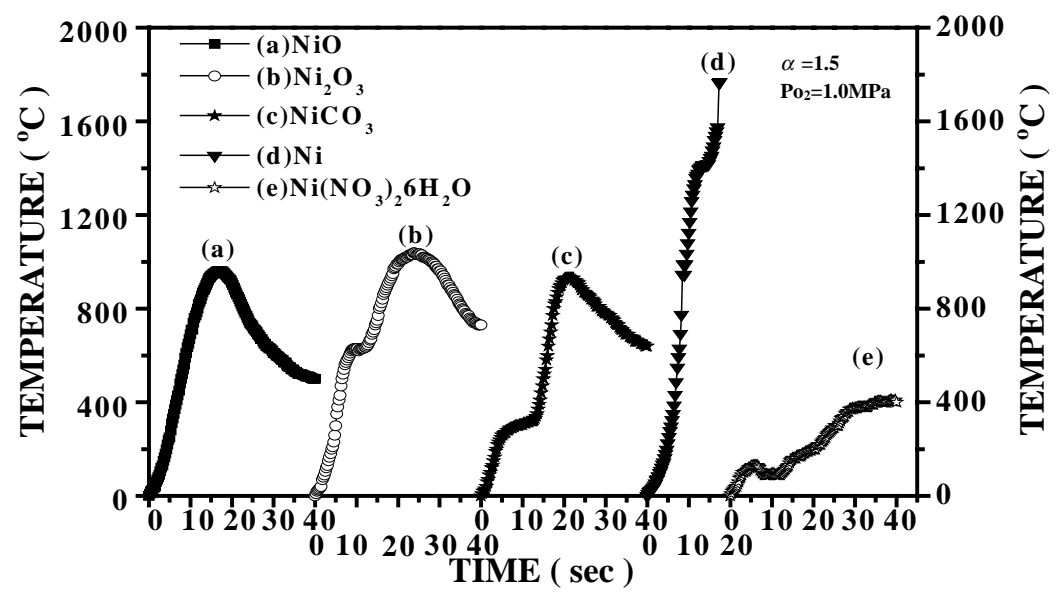

Fig. 1. Typical temperature-time histories during combustion for reactant compacts with various Ni-CSs.

ple melted due to high-temperatures. A shoulder occurred at $\sim 1550^{\circ} \mathrm{C}$ (approximately the melting points of $\mathrm{Ni}\left(1460^{\circ} \mathrm{C}\right.$ ) and $\left.\mathrm{Fe}\left(1536^{\circ} \mathrm{C}\right)\right)$. Experimental observation also found that many drops appeared at the surface of the compact during the combustion. The shoulder is thus suggested to be caused by the melting of metal particles while the drops are the metal droplets. In the case of $\mathrm{Ni}\left(\mathrm{NO}_{3}\right)_{2}+\mathrm{Fe}_{2} \mathrm{O}_{3}+\mathrm{Fe}$, the reactant compact melted and boiled quite soon during the heating stage, breaking down the compact. As evidenced by thermocouple measurement, the temperature increased slowly and, after a period of time, it hovered at around $400^{\circ} \mathrm{C}$. The SHS reaction did not seem to have started since the temperature was relatively low when compared with other cases. $\mathrm{Ni}\left(\mathrm{NO}_{3}\right)_{2}$ is thus not a suitable reactant in SHS due to its low melting point and high hygroscopicity.

\subsection{Effect of various $\mathrm{Ni}$-CSs}

Fig. 2 shows the XRD patterns of the products synthesized with the five kinds of Ni-CSs. In these experiments, the $\alpha$ value was kept at 1.5 and the $\mathrm{O}_{2}$ pressure was set at $1.0 \mathrm{MPa}$. The characteristic peaks of $\mathrm{NiFe}_{2} \mathrm{O}_{4}$ were observed for all cases. By comparing the ratio of the XRD peaks of $\mathrm{NiFe}_{2} \mathrm{O}_{4}$ to $\mathrm{Fe}_{2} \mathrm{O}_{3}$, the product synthesized with $\mathrm{Ni}_{2} \mathrm{O}_{3}$ appeared to have the highest conversion because only the characteristic peaks of $\mathrm{NiFe}_{2} \mathrm{O}_{4}$ were observed. In addition, $\mathrm{NiO}$ and $\mathrm{Fe}_{2} \mathrm{O}_{3}$ were also found in the products synthesized with the other Ni-CSs except $\mathrm{Ni}_{2} \mathrm{O}_{3}$. The use of $\mathrm{Ni}_{2} \mathrm{O}_{3}$ may exert two effects to promote the SHS reaction and thus obtain the highest conversion. First, the oxygen generated by the decomposition of $\mathrm{Ni}_{2} \mathrm{O}_{3}$ can be an extra supply to the SHS reaction (i.e., internal oxygen source). Second, decomposition of $\mathrm{Ni}_{2} \mathrm{O}_{3}$ results in evolution of smoke which generates numerous open pores inside the reactant compact. These open pores are soon filled with oxygen flowing from outside the compact (i.e., external oxygen source). However, when $\mathrm{NiCO}_{3}$ was used as the Ni-CS, the dilution effect of $\mathrm{CO}_{2}$ produced by the decomposition of $\mathrm{NiCO}_{3}$ probably offset the effect of the open pores and thus the residuals $\left(\mathrm{Fe}_{2} \mathrm{O}_{3}\right.$ and $\mathrm{NiO}$ ) were also detected in the product.

\subsection{Effect of oxygen pressure}

Fig. 3 shows the effect of oxygen pressure on product formation using $\mathrm{Ni}_{2} \mathrm{O}_{3}$ as $\mathrm{Ni}-\mathrm{CS}$ with the $\alpha$ value as 1.5 . As indicated by the XRD patterns, product formation was enhanced by increasing $\mathrm{O}_{2}$ pressure. When the oxygen pressure is higher than 1.0 MPa, only the characteristic peaks of $\mathrm{Ni}$-ferrite can be clearly observed in the X-ray spectra of the products. The oxygen outside the reactant compact is thus considered as the major source of the oxidizing agent required to promote combustion of the reactant compact. During SHS, oxygen is involved in the reaction. The penetration of oxygen from the environment into the combustion zone

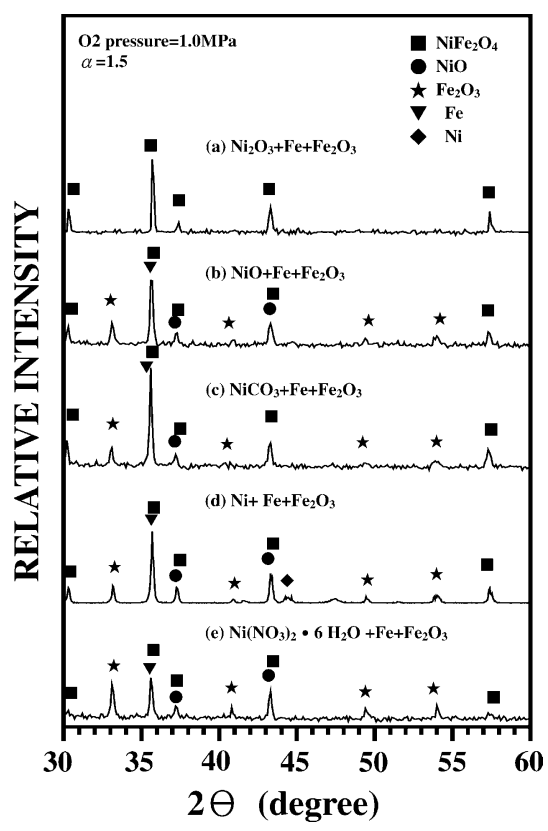

Fig. 2. XRD patterns of the products synthesized using various Ni-CSs. 


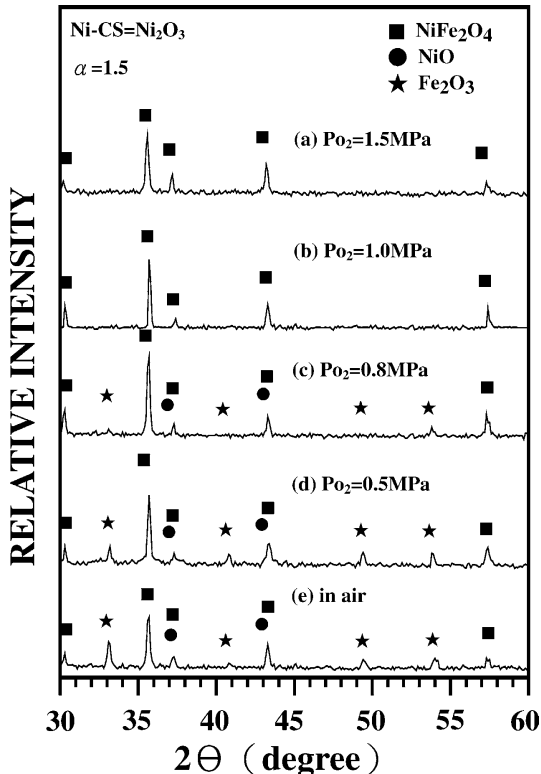

Fig. 3. Effect of $\mathrm{O}_{2}$ pressure on product formation.

is one of the main kinetic potential barriers. If the reaction is carried out under a low oxygen pressure, the product conversion is low because of the shortage of oxygen and the lack of permeability. In contrast, high oxygen pressure enhances the formation of Ni-ferrite because of the increase in the amount of oxygen available for combustion and the close proximity between particles.

\subsection{Effect of iron content}

Fig. 4 shows the effect of iron content on product formation using $\mathrm{Ni}_{2} \mathrm{O}_{3}$ as the Ni-CS and with $\mathrm{O}_{2}$ pressure kept at $1.0 \mathrm{MPa}$. It was found that, when the $\alpha$ value was below 0.5 , the combustion reaction cannot be self-sustained. As in-

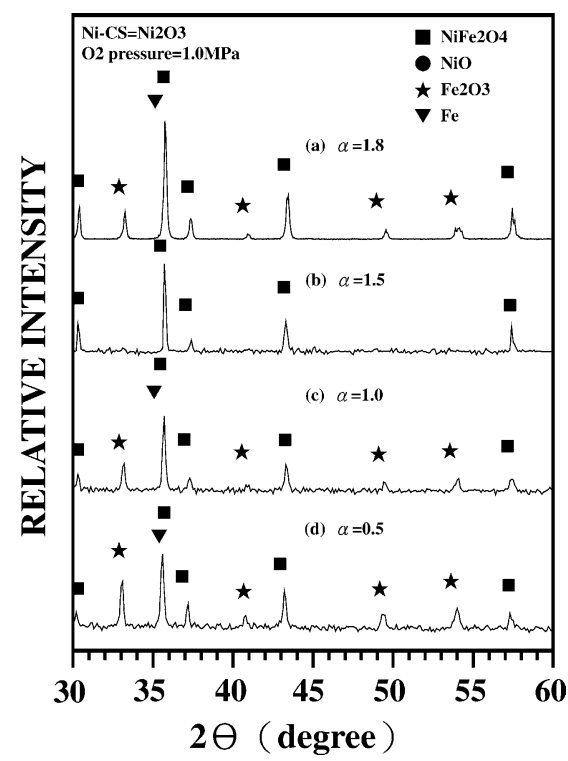

Fig. 4. Effect of iron content on product formation.

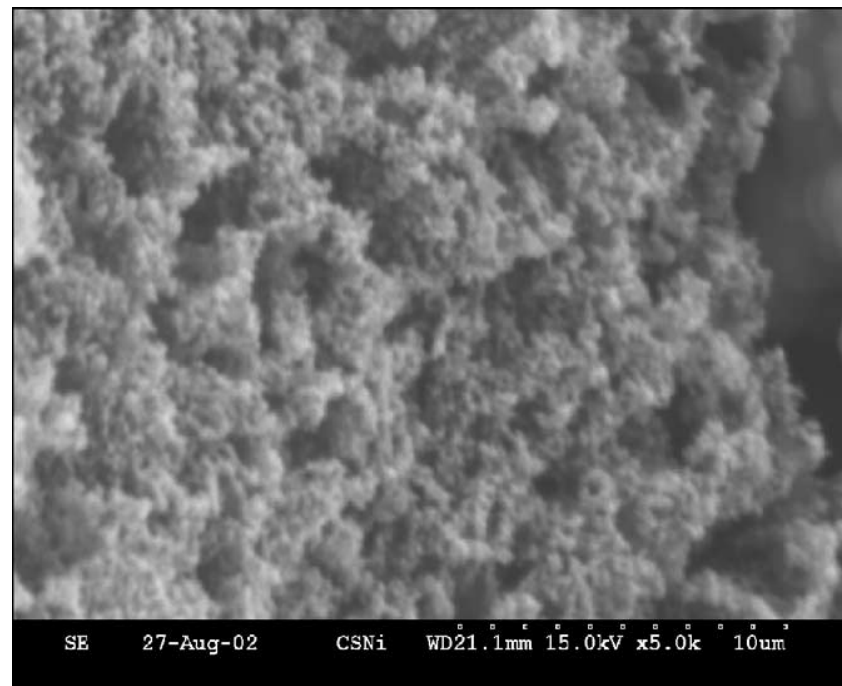

Fig. 5. Typical SEM photograph of the as-synthesized product (Ni-CS $=\mathrm{Ni}_{2} \mathrm{O}_{3}, \mathrm{O}_{2}$ pressure $=1.0 \mathrm{MPa}$ and $\alpha=1.5$ ).

dicated by the XRD patterns, product conversion increases by increasing the $\alpha$ value initially. As the value increases to 1.5 , the combustion reaction proceeds thoroughly, and only the characteristic peaks of $\mathrm{NiFe}_{2} \mathrm{O}_{4}$ are observed in the synthesized product. In this condition, the as-synthesized product is porous and composed mainly of agglomerated fine particles with submicron size $(0.1-0.5 \mu \mathrm{m}$, see Fig. 5). As mentioned above, it is suggested that the decomposition of $\mathrm{Ni}_{2} \mathrm{O}_{3}$ causes the evolution of considerable amount of oxygen, which generates a lot of open pores and keeps the powders loosely agglomerated. However, when $\alpha=1.8$, additional diffraction peaks belonging to the $\mathrm{Fe}_{2} \mathrm{O}_{3}$ and $\mathrm{NiO}$ phases are detected in the XRD patterns. The peaks of $\mathrm{Fe}$ are also found in some cases when $1.8 \leq \alpha \leq 2.0$. In this case, a melting of the as-synthesized products can be observed, as shown in Fig. 6. The melt was identified to be Fe by point analysis of energy dispersive spectrum (EDS). It is the heat released from the oxidation reaction of the iron metal $\left(\Delta H_{\mathrm{r}}=-800 \mathrm{~kJ} / \mathrm{mol}\right)$ that sustains combustion between $\mathrm{Ni}_{2} \mathrm{O}_{3}, \mathrm{Fe}$ and $\mathrm{Fe}_{2} \mathrm{O}_{3}$. For $1.8 \leq \alpha \leq 2.0$, based on experimental observations, it is found that certain amounts of Fe particles melted and flowed out of the reactant compact without participating in synthesis. This is largely due to the excessively high combustion temperature (above $1600^{\circ} \mathrm{C}$ as measured by thermocouples). Moreover, the melting and coalescence of the $\mathrm{Fe}$ particles eliminates the open pores created by the decomposition of $\mathrm{Ni}_{2} \mathrm{O}_{3}$ and thus inhibits external oxygen from flowing inside the reactant compact, decreasing product conversion. The optimal $\alpha$ value was therefore chosen at 1.5 for SHS.

\subsection{Morphology observation of sintered sample}

Pure Ni-ferrite powders from the as-synthesized product were pressed at $6000 \mathrm{~kg} / \mathrm{cm}^{2}$ (green density $=45 \%$ of 


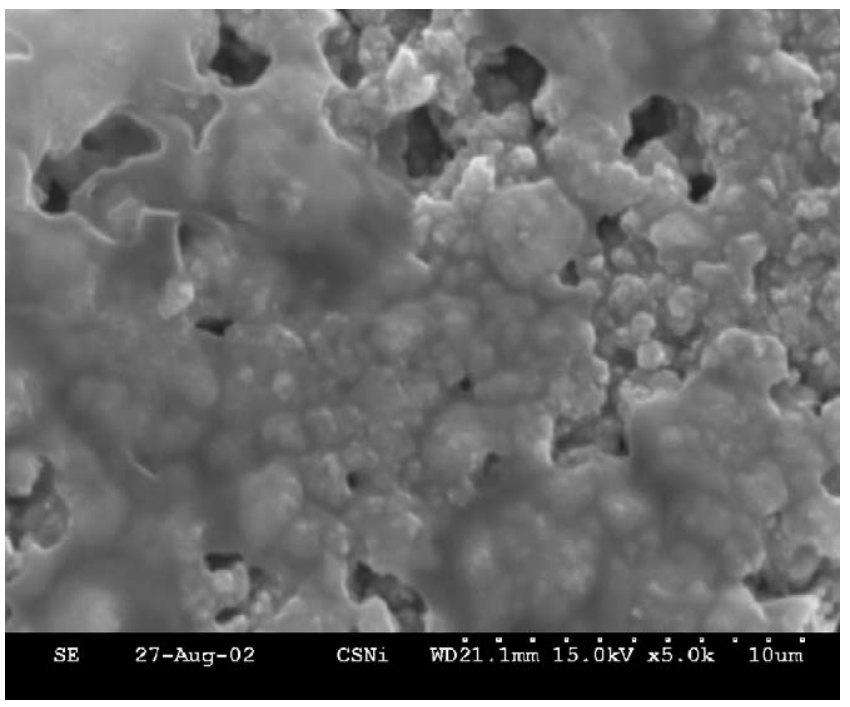

Fig. 6. Typical SEM photograph of the combustion product at a high iron content condition (Ni-CS $=\mathrm{Ni}_{2} \mathrm{O}_{3}, \mathrm{O}_{2}$ pressure $=1.0 \mathrm{MPa}$ and $\alpha=1.8$ ).

the theoretical value) and sintered at $950^{\circ} \mathrm{C}$ for $2 \mathrm{~h}$ in air. Fig. 7 shows the SEM photograph for the fractured surface of the sintered sample. A well-densified microstructure can be observed from the photograph, indicating that the as-synthesized Ni-ferrite powder can be densified at $950^{\circ} \mathrm{C}$. The texture of the sintered sample is homogeneous, consisting of polyhedral grains with grain sizes in the range of $1-3 \mu \mathrm{m}$.

\subsection{Measurement of magnetic property}

As demonstrated by the VSM hysteresis loops (Fig. 7), the Ni-ferrite prepared by combustion reaction shows good soft-magnetic properties, comparable to excellent commercial samples produced by the solid reaction method. From the loops, it is also observed that the SHS Ni-ferrite possesses higher maximum saturation magnetization $\left(M_{\mathrm{s}}\right)$ and

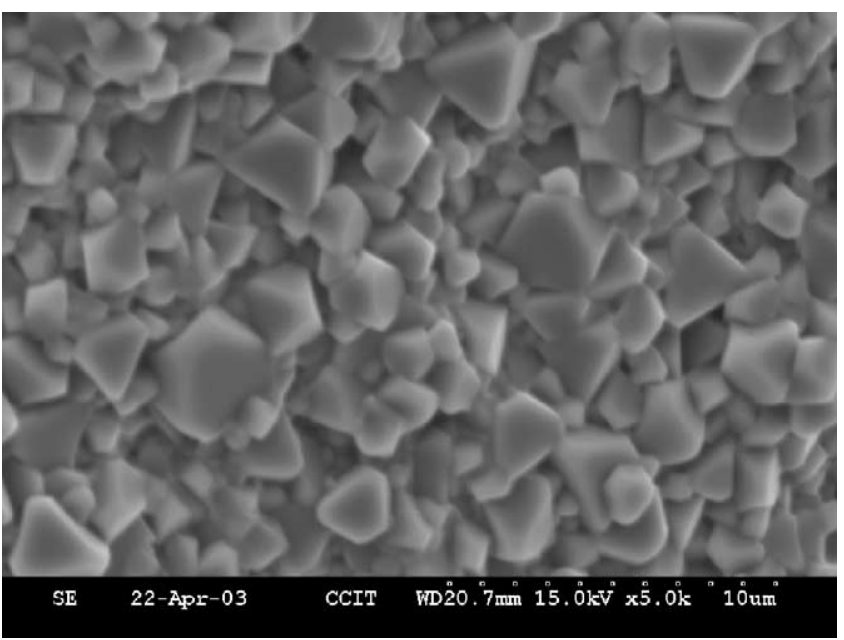

Fig. 7. SEM photograph of the sintered sample.
Table 2

Magnetic properties of Ni-ferrite powders synthesized at different oxygen pressures

\begin{tabular}{llll}
\hline $\begin{array}{l}\mathrm{O}_{2} \text { pressure } \\
(\mathrm{MPa})\end{array}$ & $\begin{array}{l}\text { Saturation } \\
\text { magnetization } \\
\left(M_{\mathrm{s}}\right)\left(\mathrm{A} \mathrm{m}^{2} / \mathrm{kg}\right)\end{array}$ & $\begin{array}{l}\text { Residual } \\
\text { magnetization } \\
\left(M_{\mathrm{r}}\right)\left(\mathrm{A} \mathrm{m}^{2} / \mathrm{kg}\right)\end{array}$ & $\begin{array}{l}\text { Coercive force } \\
\left(H_{\mathrm{c}}\right)(\mathrm{kA} / \mathrm{m})\end{array}$ \\
\hline In air $(\approx 0.02)$ & 30.53 & 13.68 & 17.820 \\
0.5 & 39.28 & 10.25 & 12.484 \\
0.8 & 43.31 & 9.16 & 10.461 \\
1.0 & 47.59 & 8.38 & 8.655 \\
\hline
\end{tabular}

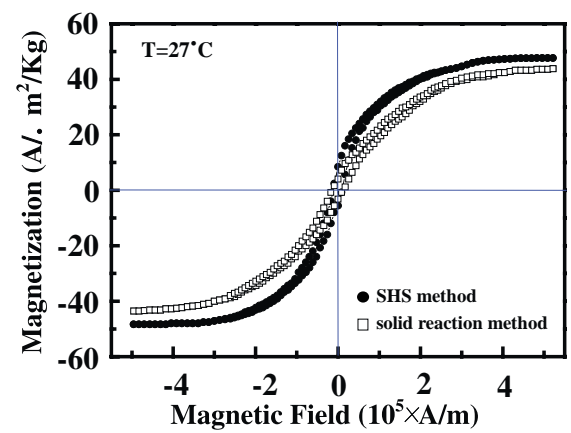

Fig. 8. Hysteresis loops (measured at $27^{\circ} \mathrm{C}$ ) for the Ni-ferrite synthesized from the SHS reaction of $0.5 \mathrm{Ni}_{2} \mathrm{O}_{3}+1.5 \mathrm{Fe}+0.25 \mathrm{Fe}_{2} \mathrm{O}_{3}$ under $\mathrm{O}_{2}$ pressure $=1.0 \mathrm{MPa}$, as compared with commercial $\mathrm{NiFe}_{2} \mathrm{O}_{4}$ prepared by solid reaction method.

susceptibility $(\Delta M / \Delta H)$. The residual magnetization $\left(M_{\mathrm{r}}\right)$ and coercive force $\left(H_{\mathrm{c}}\right)$ are relatively lower when compared with the conventionally synthesized sample.

Table 2 lists the magnetic properties of the product powders synthesized under different oxygen partial pressures. The maximum saturation magnetization increases with increasing oxygen pressure, while the residual and coercive force decrease. The XRD patterns of the synthesized products (see Fig. 3) and magnetic measurements indicate that the improved ferromagnetic properties of the synthesized products are attributed to the increased $\mathrm{Ni}$-ferrite formation due to oxygen pressure during combustion (Fig. 8).

\section{Conclusion}

The following conclusions can be drawn from this study:

1. A SHS process has been developed for the synthesis of $\mathrm{NiFe}_{2} \mathrm{O}_{4}$ powder. A reactant compact composed of $\mathrm{Fe}, \mathrm{Fe}_{2} \mathrm{O}_{3}$ and a $\mathrm{Ni}-\mathrm{CS}\left(\mathrm{Ni}_{2} \mathrm{O}_{3}, \mathrm{NiO}, \mathrm{NiCO}_{3}\right.$, $\mathrm{Ni}\left(\mathrm{NO}_{3}\right)_{2} \cdot 6 \mathrm{H}_{2} \mathrm{O}$, or $\mathrm{Ni}$ ) powders is heated in air or oxygen atmosphere $(\leq 1.5 \mathrm{MPa})$, and combustion is carried out to convert it to $\mathrm{NiFe}_{2} \mathrm{O}_{4}$ powder. Characteristic peaks of Ni-ferrite were observed after combustion based on the XRD patterns of these products.

2. The product synthesized by using $\mathrm{Ni}_{2} \mathrm{O}_{3}$ appears to have the highest product conversion. During $\mathrm{SHS}, \mathrm{Ni}_{2} \mathrm{O}_{3}$ decomposes to generate oxygen, and thus it may act as an internal oxygen source. Moreover, upon the decomposi- 
tion of $\mathrm{Ni}_{2} \mathrm{O}_{3}$, the reactant compact becomes porous, enabling external oxygen to flow easily into the compact. The two effects enhance the formation of the Ni-ferrite and thus results in high product conversion.

3. When using $\mathrm{Ni}_{2} \mathrm{O}_{3}$ as the Ni-CS, the product conversion was found to be affected by the iron content and the oxygen pressure. The optimum values for obtaining high product yields were found to be $\alpha=1.5$ and $\mathrm{O}_{2}$ pressure $=1.0 \mathrm{MPa}$, respectively.

4. By using $\mathrm{Ni}_{2} \mathrm{O}_{3}$, with $\alpha=1.5$ and $P_{\mathrm{O}_{2}}=1.0 \mathrm{MPa}$, it is found that the synthesized product is porous and mainly composed of agglomerated fine particles with submicron size. Compared with the commercial sample prepared by solid reaction method, SHS gives Ni-ferrite powder better magnetic properties.

5. The magnetic properties of the synthesized products depend on the oxygen pressure during combustion. The maximum saturation magnetization increases with oxygen pressure, while residual magnetization and coercive force decrease. The improved magnetic properties are attributed to the increased $\mathrm{Ni}$-ferrite formation at a given combustion condition.

\section{Acknowledgements}

Support for this research by the National Science Council of the Republic of China under Grant No. NSC 90-2214-E-014-002 is gratefully acknowledged.

\section{References}

[1] A.H. Morrish, K. Haneda, J. Appl. Phys. 52 (1981) 2497.

[2] A.S. Albuquerque, J.D. Ardisson, W.A.A. Macedo, J.L. López, R Paniago, A.I.C. Persiano, J. Magn. Magn. Mater. 226-230 (2001) 1379.

[3] J. Roberts, High Frequency Applications of Ferrites, English University Press, London, 1960.

[4] D. Vladikova, L. Ilkov, S. Karbanov, Phys. Stat. Sol. (a) 111 (1989) 145.

[5] A. Verma, T.C. Goel, R.G. Mendirtta, J. Magn. Magn. Mater. 210 (2000) 274

[6] V.V. Pankov, M. Pernet, P. Germi, P. Mollard, J. Magn. Magn. Mater 120 (1993) 69.

[7] P.S.A. Kumar, J.J. Shrotri, C.E. Deshpande, J. Appl. Phys. 81 (1997) 4788.

[8] Z.X. Yue, J. Zhou, L.T. Li, H.G. Zhang, Z.L. Gui, J. Magn. Magn. Mater. 208 (2000) 50.

[9] A.G. Merzhanov, I.P. Borovinskaya, Combust. Sci. Technol. 10 (1975) 195

[10] Z.A. Munir, Ceram. Bull. 67 (2) (1988) 342.

[11] J.F. Crider, Ceram. Eng. Sci. Proc. 3 (9-10) (1982) 519.

[12] P.B. Avakyan, M.D. Nersesyan, A.G. Merzhanov, Am. Ceram. Soc. Bull. 75 (1996) 50.

[13] G. Elwin, I.P. Parkin, Q.T. Bui, L.F. Barquín, Q.A. Pankhurst, A.V Komarov, Y.G. Morozov, J. Mater. Sci. Lett. 16 (1997) 1237.

[14] Y. Choi, N.I. Cho, H.C. Kim, Y.D. Hahn, J. Mater. Sci., Mater. Electron. 11 (2000) 25.

[15] M.J. O'Neil, A. Smith, P.E. Heckelman, The Merck Index, 13th ed., Merck, Whitehouse Station, NJ, USA, 1989, pp. 1166-1167.

[16] C.C. Hwang, S.L. Chung, J. Mater. Sci. Lett. 21 (2002) 447. 